\title{
Analysis of Some Eastern and Western Regions of Russia in the Field of ICT Development
}

\author{
Morozov Arseny Arkadevich* and Belaya Raisa Vasiljevna \\ FRC Karelian Research Center of RAS Institute of Economics Russia, Petrozavodsk; \\ morozov589@gmail.com, belaya@krc.karelia.ru
}

\begin{abstract}
Objectives: To study the difference in ICT development in the regions of the North-West Federal District and the Far Eastern Federal District. Methods/Statistical Analysis: It involves the method of analysis and synthesis. It includes, Statistical analysis of databases of Public Opinion Foundation, Institute for the Development of the Information Society (Moscow) and results of researches of the Russian scientists. Findings: Today the history of origin and development, perspective of functioning of social networks gradually turn into one of the relevant directions of scientific research, and attracts interest of representatives of different sciences: from philosophers, sociologists, economists, to experts in the sphere of ICT. In general, regions of the North Western Federal District are more prepared for development of information society. Both the populous nature of the European part of the Russian Federation, and proximity to more developed countries affects such differences. As shown by the analysis, dynamics of indexes of 2008 in regions of the FEFD goes more actively, than in regions of the North-Western Federal District. More careful research is already on and more modern data is required precisely to define growth rates of readiness of information society of the NW and the East of Russia and to make expert recommendations for further development of this area. Information or digital inequality of Russian regions can both strengthen the developed regional differentiation, and to level its existing destructive manifestations on the basis of innovative reorientation from regions, resource-intensive on the information strategy of the social and economic development. Application/Improvements: Based on this analysis, we can see the problems of the development of the digital society and try to solve them.
\end{abstract}

Keywords: Communications, Digital Economy, ICT, Network Communities, Region

\section{Introduction}

The gained popularity of scientific researchers of different areas in the perspective connected to development of the network environment is caused by the active approach of the modern Information and Communication Technologies (ICT) which are involved not only in upgrade of means and forms of existence, but also have a direct bearing on change of social characteristics of the current time. They can change kind of work of the person, social communications, organizational forms of implementation of social interactions and the social relations ${ }^{1}$. The first social Internet networks gave to users opportunities preferentially for interpersonal communication. Today they unprecedentedly extend, forcing out or replacing direct communication. Network (Internet) communications can become the tool of more active and productive dialog between society, the power and professional communities, sharing intellectual potential ${ }^{2}$.

According to internetworldstats.com, at the end of 2014 in Russia there were 103 million Internet users, and its penetration reached $70,5 \%$. For comparing, on average in the European countries penetration of the Internet by the end of 2015 is estimated at 73,5\%, and on average in all countries of the world - 46,4\%. I.e. development of the Internet in Russia is provided to a lesser extent than on average in Europe that is not surprising, considering the non-uniform structure of resettlement and extensive spatial variety of the Russian Federation. At the same time, the study of network activity of the Russian

${ }^{*}$ Author for correspondence 
users realized by FOM (on the basis of selective survey of adult population of the cities) shows its high dynamism. And 2012 became a point of a fracture in case of which specific weight of Internet users exceeded a share of the citizens who are not using networks ${ }^{3}$. For overcoming low activity of network communities an important factor is detection of demand of the most professional community for exchange of judgements. In case of great demand, the activity of interaction will probably be rather high. In case of the revealed low demand, carrying out additional researches on detection of developmental factors of professional network activity is required ${ }^{4}$.

The phenomenon of network communities took a steady position in scientific research that caused formation of a wide object and object palette, search of an adequate methodological and methodical basis of scientific search $^{5}$. The virtual social networks become zones of creation of new forms of the social and human capital which in turn accelerates process of formation information societies $^{5}$. In Russia and the neighboring countries such scientists as V. Yu. Nesterov, T. V. Yershova, Yu. E. Khokhlov, S. B. Shaposhnik, A. B. Skuratov, M. V. Sukharev, R. R. Shamsutdinov, A. S. Voronkin, and others are engaged in questions of development of information society and network communities. E.I. Goroshko's theory about information and communicative society is interesting. The author selects 5 approaches to his study: the creation of social forecasts of development of a global web; the study of the network nature of the modern society founded on internet technologies; the research of the Internet as visual image of the world; the application to a study of the Internet of postmodern concepts; the judgment of the idea of supersociety (the globalized society) as new type of society in which the Internet becomes a mandatory component ${ }^{7}$. Development of network communities and ICT on a straight line carries to development of it the phenomenon as "the smart cities".

\section{Methodology}

The institute of Development of Information Society developed the Index of readiness of regions for information society (further in the text of IRRIS). Since 2005 results of a research of this project participants are published. The index represents the measuring instrument of a level of readiness of regions to use of ICT for social and economic development. It is calculated on the basis of the indices characterizing factors of development of information society and also use of ICT in six areas (the public and municipal administration, education, health care, business, culture, households) ${ }^{9}$. For calculation of the index and its components 77 indices which the key indicators of access and use of ICT recommended by the international organizations are used. The index allows to measure differences between territorial subjects of the Russian Federation on integral indices of information development ${ }^{10}$. The index gives the chance to assess the current situation, to reveal the most problem zones from the point of view of information inequality of regions and to define zones of lag and a hindrance on the way of development of information society in territorial subjects of the Russian Federation. At open access there are data till 2014. It is possible to study reports on the index website in more detail - http://eregion.ru/polnyi-otchet.

IRRIS is separated on:

- the index components of factors of electronic development (human capital, ICT infrastructure, economic environment);

- the index components of use of ICT for development (ICT in business, culture, medicine, education, households, organs of state authorities).

The procedure of normalization is used for creation of the index. The technique of normalization is used for preparation of the Index is similar to the procedure which is used in the composite index of development of ICT (ICT Development Index, IDI) developed by the International Telecommunication Union according to the decision of the World summit on development of information society. The specified procedure is based on calculation (by division) the relations of the current measure value for the territorial subject of the Russian Federation to the "reference" (normalizing) it value - usually maximally possible on this index (in case of share indices it is 100\%). Assessment of an index was calculated by the following formula: the normalized value (assessment) of the index of the region of $X=R x / R n$, where $R x-$ the measure value for the region $\mathrm{x}, \mathrm{Rn}$ - the normalizing ("reference") measure value. Thus, if the region has "reference" (usually maximally possible) measure value, its assessment on this index is equal 1 if the value is less "reference", it's the normalized value will be less than 1 , and normalized to value it is possible to determine by value as far as the region lags 
behind reference value. For assessment of indices which increase in value has negative character (for example, a share of food in costs breakdown of households) other formula was used: The normalized value (assessment) of an index of the region of $X=R n / R x$. As the normalizing ("reference") measure values in case of share indices (their majority) the maximally possible $100 \%$ value undertook ${ }^{11}$. In some directions (in particular ICT infrastructure, the economic environment) sub-indexes were calculated directly, on the basis of the being their indicators without introduction and calculation of the intermediate parameters (as in case of the sub-index of "ICT in culture", etc.) $)^{12}$.

\section{Discussion and Results}

Figure 1 dynamics of the index on some Northwest and Far East regions of the Russian Federation is given.

Interestingly, the growth rates of the index in the Nenets Autonomous Okrug (further the NAO) are the lowest concerning other regions. This region entered in top-20 regions of the Russian Federation on index indices in 2008, and already to the 2013-2014 transferred to the 56th place $^{13}$ due to lowering of growth rates of the index. Against the background of a low-population and its remoteness from the large centers which are followed by outflow of the human capital from the region there is a problem of feeble development of ICT infrastructure. The dynamics of growth of the integral index of Murmansk region and the Republic of Karelia is characterized by higher rates in comparison with St. Petersburg (further $\mathrm{SPb}$ ). Such external factors as closeness to foreign countries in connection with border situation promote the high growth of an index in the subsidized resource oriented region Karelia, and also closeness to the large megalopolis - to St. Petersburg that promotes diffusion of innovations, exerting a positive impact on development and use of ICT in the region.

The situation in regions of the Far Eastern Federal District (further the FEFD) developed so that among the considered regions Primorsky Krai is the lagging most behind. For 2009-2011 there was no development in the field. Khabarovsk Krai is similar to the Republic of Karelia in the field. Development since 2008 in regions of the FEFD goes more actively, than in regions of the NorthWestern Federal District (further the NWFD).

Internal regional distinctions of the considered subjects reveal on the basis of a ratio two the index components, including factors of ICT use for development and factors of electronic development (Figure 2).

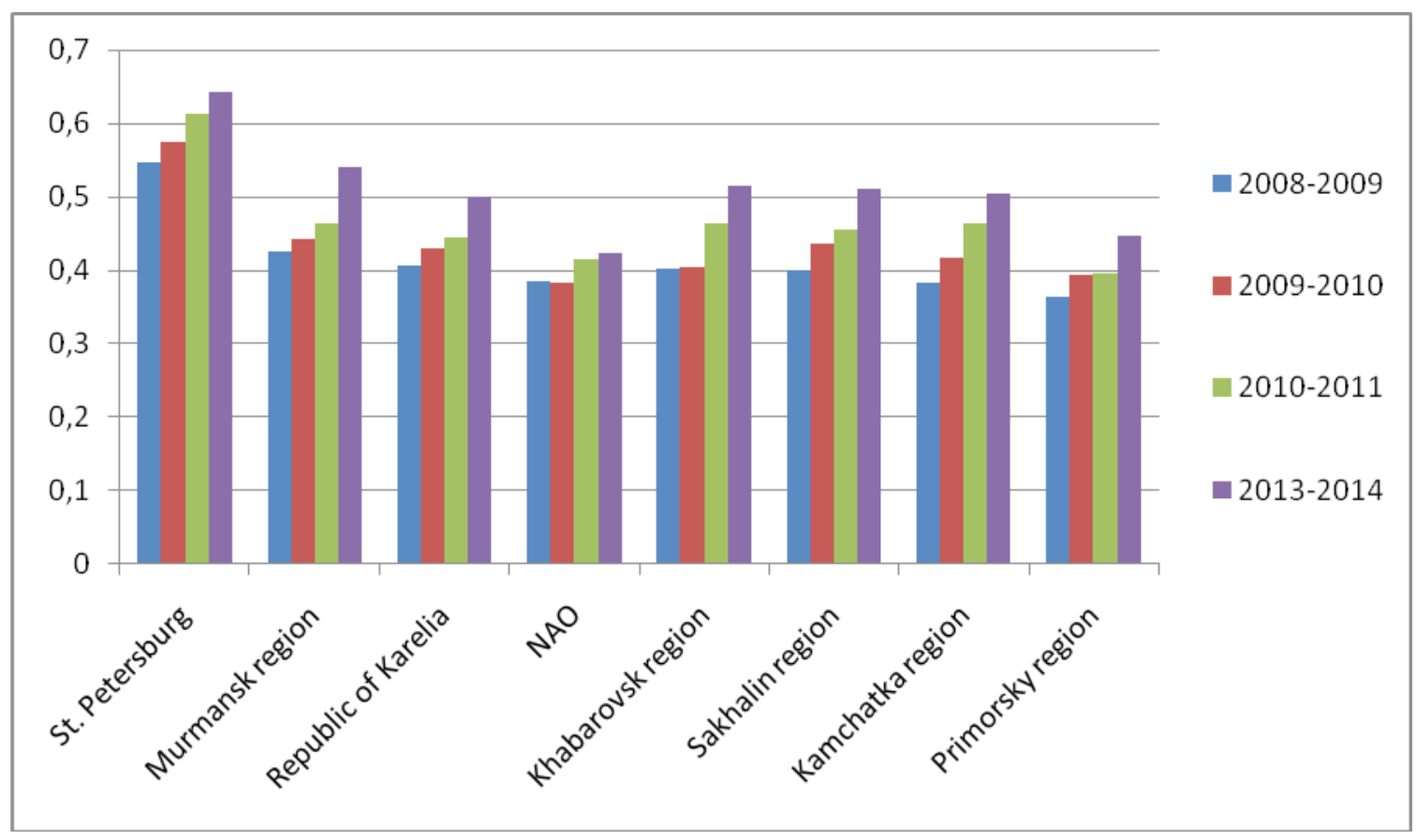

Figure 1. Dynamics of the readiness index for the information society of some regions of the Russia 2008-2014 ${ }^{15}$ 


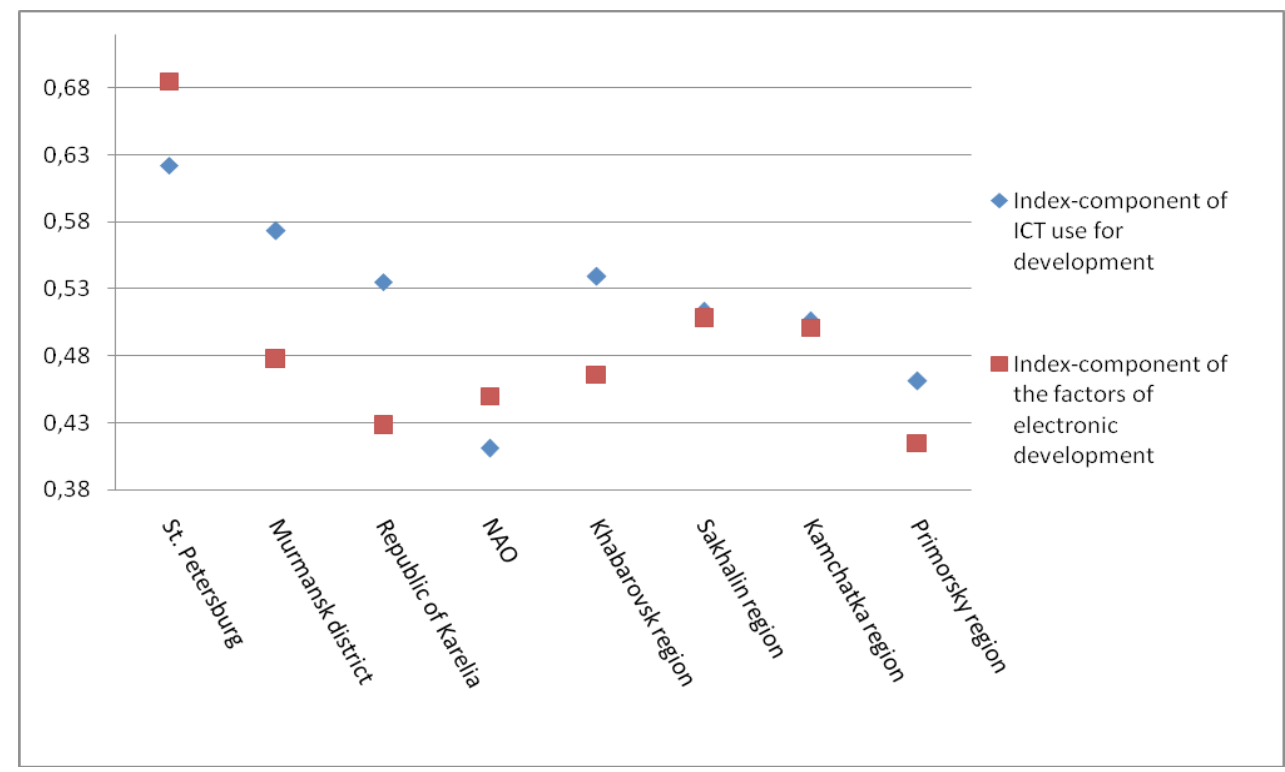

Figure 2. The ratio of the index components by regions of the North-Western Federal District and the Russian Far East Federal District, 2013-2014 ${ }^{16}$.

That fact that in regions St. Petersburg and the NAO value the index component of electronic development (the human capital, the ICT infrastructure, the economic environment) is higher than value the index component of ICT use for development attracts attention (in business, culture, medicine, education, etc.). The reverse ratios of indexes are watched in Murmansk region and Karelia. At the same time the highest values of both indexes at St. Petersburg. In the Republic of Karelia (further the RK) against the background of the biggest gap between values two considered the index components the lowest value among four regions the index component of electronic development, including below than at the NAO is recorded. Bit-by-bit comparing of the index component of factors of electronic development of the RK and the NAO shows what its low values in RK is caused by a low measure value "the economic environment" ${ }^{14}$.

In regions of the FEFD two regions - the Sakhalin region and Kamchatka Krai are of interest. Both indices of indexes are in these regions approximately at one level that proves static development of these areas of both components of the index and consequently and generally readiness for information society. Also interestingly the fact that in one of the considered regions the index components of factors of electronic development does not exceed the index components of ICT use for development. In indices across Khabarovsk Krai the wide spacing between indexes is marked.

\section{Conclusion}

North Western Federal District are more prepared for development of information society. Both the populous nature of the European part of the Russian Federation, and proximity to more developed countries affects such difference. As showed the analysis, dynamics of indexes of 2008 in regions of the FEFD goes more actively, than in regions of the North-Western Federal District (including St. Petersburg). More careful research is already on and more modern data is required precisely to define growth rates of readiness of information society of the North-West and the East of Russia and to make expert recommendations for further development of this area.

The digital inequality of Russian regions can both strengthen the developed regional differentiation, and to level its existing destructive manifestations on the basis of innovative reorientation from regions, resource-intensive on the information strategy of the social and economic development.

\section{Acknowledgement}

Article is executed within the project of the Russian Federal Property Fund "Research and development of models of formation of regional social and economic network communities" (17-06-00691). 
The article was carried out within the framework of the state assignment of the Federal Agency of Scientific Organizations of Russia "The role of human capital: new economic theories - modern challenges" (0224-20150003).

\section{References}

1. Socialization in Virtual Groups [Internet]. [cited 2003 Apr 01]. Available from: crossref.

2. Public monitoring of activities of organs of the regional government and local government with use information and communication technologies [Internet]. [cited 2017 Nov 29]. Available from: crossref.

3. Development of the Internet in regions of Russia, 2016. Audience of the Internet and reserves of growth [Internet]. [cited 2016 Mar]. Available from: crossref.

4. Smart cities and network community's development [Internet]. [cited 2017 Dec]. Available from: crossref.

5. Maximova $\mathrm{OB}$. The individual and society in a mirror of the Internet: the virtual dimension of the communicative personality and her representation in network community.
Historical, philosophical, political and jurisprudence, cultural science and art criticism, questions of the theory and practice. Kazan; 2011. p. 146-50.

6. Virtual Community for a Creative City [Internet]. [cited $2015 \mathrm{Feb} 24]$. Available from: crossref.

7. Goroshko EI. Information and communicative society in gender measurement. Kharkov, KHLP Liburkina L.M. Publication; 2009. p. 1-816.

8. Caragliu A, Del Bo C, Nukamp P. Smart cities in Europe. 3rd Central European Conference in Regional Science CERS; 2009. p. 45-59.

9. Index of readiness of regions of Russia for information society 2010-2011; 2012. p. 1-466.

10. Index of readiness of regions of Russia for information society 2009-2010; 2011. p. 1-364.

11. Index of readiness of regions of Russia for information society 2013-2014; 2015. p. 1-536.

12. Index of readiness of regions of Russia for information society. 2008-2009; 2010. p. 1-296.

13. Morozov AA, Belaya RV, Morozova TV. Regional features of development of network communities in Russia: example of the Republic of Karelia. Creative economy. 2017; 11(10):1077-92. 